\title{
Biogerontological research in Europe: special issue
}

\author{
Vladimir Kh. Khavinson - Suresh I. S. Rattan
}

Received: 7 December 2010/ Accepted: 14 December 2010/Published online: 24 December 2010

(C) Springer Science+Business Media B.V. 2010

As the current President and the Secretary, respectively, of the Biological Section of the International Association of Gerontology and Geriatrics (IAGG; European Region), we are delighted to present this special issue of Biogerontology on the occasion of the 7th European Congress of IAGG at Bologna (April 14-17, 2011), providing an overview of the state of biogerontological research in various countries in Europe.

Research on the biological basis of ageing includes: (1) describing the phenotype of ageing at the level of organs, systems, tissues, cells, intra- and inter-cellular pathways, and molecules; (2) unravelling the biochemical and molecular mechanisms of age-related changes; (3) identifying genes that affect the quality and duration of lifespan; (4) identifying the rate-limiting steps which lead to the emergence of age-related diseases; and (5) screening, testing and developing evidence-based effective interventions to modulate ageing and to extend the health-span. Different countries have different priority areas for research, which keep on changing and evolving in accordance with the changing social, political and economic trends.

There are 34 national gerontological research societies in Europe, and they are expected to maintain databases with respect to all aspects of ageing research, including biological, sociological, psychological, and clinical. From about mid-2009, we approached them with an invitation to present a brief overview of the state of biogerontological research in their respective country. We are delighted to present the first series of such reports from Austria, Czech Republic, Finland, Georgia, Israel, Italy, Russia, Serbia, Spain, Turkey and Ukraine in this special issue of Biogerontology, and we hope that similar reports from the other countries will be published in the future issues.

V. Kh. Khavinson

St. Petersburg Institute of Bioregulation and Gerontology,

St. Petersburg, Russia

S. I. S. Rattan ( $₫)$

Laboratory of Cellular Ageing, Department of Molecular Biology, Aarhus University, Aarhus, Denmark

e-mail: rattan@mb.au.dk 